\title{
Prediction of Surface Roughness using Sensor Fusion Regression Model
}

\author{
Anuja Beatrice B, Leo Dev Wins K, Ebenezer Jacob Dhas D S, Arul Kirubakaran D
}

\begin{abstract}
Surface roughness decides the quality of machined components during machining processes. Output parameters namely cutting temperature, cutting force, tool wear, vibration etc. have direct influence on surface roughness of machined components. It is anticipated that better prediction would be possible if the above mentioned parameters are collectively considered with machining parameters. In this investigation, an effort was made to fuse machining parameters with cutting temperature to predict surface roughness while machining $\mathrm{H13}$ steel. The developed regression model was tested for its ability to predict surface quality. The results proved that the developed sensor fusion regression model can be used for better prediction of cutting performance.
\end{abstract}

Keywords: Regression analysis, Hard turning, Minimal cutting fluid application, Surface roughness, Sensor fusion.

\section{INTRODUCTION}

Surface roughness is one of the key parameter deciding the worth of the machined components. Machining under hardened state is becoming popular due to the benefits such as less cycle time, low manufacturing cost and improvement in quality. Hard turning process requires huge quantity of cutting fluid in order to decrease the heat and frictional resistance produced during machining to achieve good quality. Therefore, hard turning is generally carried out under flood cooling.

Even though there are lot of benefits associated with the supply of cutting fluids during metal cutting, it creates negative impacts such as environmental pollution, additional handling / disposal expenses and health issues [1]. Dry machining completely avoids cutting fluid usage but it incur additional expenses in terms of added rigidity of cutting tools and machine tools in withstanding high temperature and pressure [2]. For minimizing the adverse impacts of cutting fluid, Minimal Cutting Fluid Application (MCFA) technique is developed. In MCFA, insignificant amount of cutting fluid is applied as tiny particles at great speed into the contact zones in order to achieve the benefits of both dry machining and added benefits achievable through the application of cutting fluid.

Models associated to metal cutting are basically nonlinear. So as to achieve precise results, mathematical models are developed with assumptions. Bhuiyan et al. found that Acoustic emission and vibration can successfully respond to output response in turning when surface

\footnotetext{
Revised Manuscript Received on September 14, 2019.

Anuja Beatrice B, Sri Krishna Arts and Science College, Coimbatore, Tamilnadu, India.

Leo Dev Wins K, Karunya Institute of Technology and Sciences, Coimbatore, Tamilnadu, India.(E-mail: leo@karunya.edu)

Ebenezer Jacob Dhas D S, Karunya Institute of Technology and Sciences, Coimbatore, Tamilnadu, India.

Arul Kirubakaran D, Karunya Institute of Technology and Sciences, Coimbatore, Tamilnadu, India.
}

roughness and tool wear are fused with the other two signals [3].

A nonlinear regression model was developed by Feng and Wang to predict surface quality while turning of 8620 steel with input parameters namely hardness of workpiece, cutting time, feed, spindle speed, depth of cut, and point angle of the tool [4].

Garcoa et al found that multi-sensor fusion can provide substantial enhancement for quality control [5]. It was found from the literatures that regression models are effectively used by many researchers for predicting surface finish during hard turning [6] but limited works are reported on surface roughness modelling of hard turning with MCFA. The current investigation focusses on the fusion of cutting parameter signals with the cutting temperature signals using regression model for predicting surface finish. The investigation revealed the close match between the experimental results and the predicted results by sensor fusion regression model.

\section{EXPERIMENTATION}

H13 tool steel with 43 HRC hardness was chosen as workpiece material. It is widely used in die casting industries. The selected work material was a cylindrical rod with $65 \mathrm{~mm}$ dia and $350 \mathrm{~mm}$ length. Table 1 shows the percentage of elements in the workpiece.

Table 1 Weight \% of elements in H13 steel

\begin{tabular}{lllllll}
\hline $\mathrm{C}$ & $\mathrm{Cr}$ & $\mathrm{Mo}$ & $\mathrm{Si}$ & $\mathrm{Mn}$ & $\mathrm{P}$ & $\mathrm{Fe}$ \\
\hline 0.430 & 5.020 & 1.130 & 1.080 & 0.214 & 0.033 & balance
\end{tabular}

The specification of the tool holder was PSBNR 2525 M12 and the specification of the insert was SNMG 120408. The selection of tool holder and insert was based on the suggestions by M/s TaeguTec India (P) Limited. The cutting fluid was formulated in this research considering the added effectiveness expected in reducing friction and heat generation at minimal application. The water based cutting fluid was formulated by adding mineral oil with other important ingredients [7].

Fig. 1 presents the setup used for experimentation. It contains a Kirloskar lathe which was used for conducting the turning experiments along with other accessories for changing feed rate, cutting velocity and minimal cutting fluid application. 


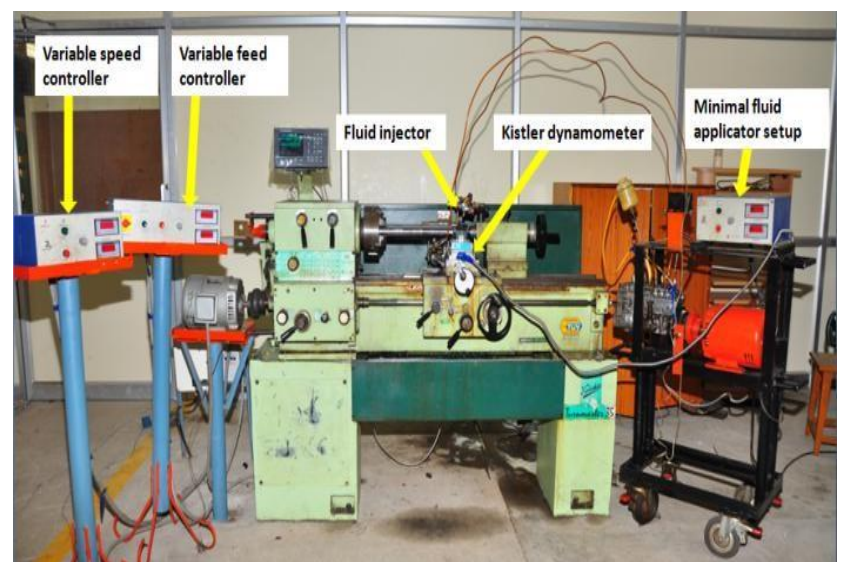

Figure 1: Experimental set up

The levels and range of input parameters were carefully chosen by conducting preliminary experiments. The cutting variables and their levels are presented in Table 2. Cutting temperature and surface finish were measured using Amprobe Infrared thermometer (IR 750) and surface roughness measuring instrument (Mitutoyo, SJ-210) respectively.
Table 2: Cutting variables and their levels

\begin{tabular}{llll}
\hline Feed $(\mathrm{mm} / \mathrm{rev})$ & 0.050 & 0.075 & 0.100 \\
Cutting velocity $(\mathrm{m} / \mathrm{min})$ & 75.0 & 95.0 & 115.0 \\
Depth of cut $(\mathrm{mm})$ & 0.50 & 0.75 & 1.00 \\
\hline
\end{tabular}

\section{DESIGN OF EXPERIMENTS}

Cutting experiments were carried out with two repetitions based on Taguchi's L27 orthogonal array considering the input variables viz. feed, cutting velocity and depth of cut and varying them at three levels. The parameters related to cutting fluid application were maintained constant [8]. Table 3 shows the variation of input parameters and the results obtained based on L27 orthogonal array.

\section{REGRESSION ANALYSIS WITH SENSOR FUSION}

It was decided to fuse cutting temperature signals with cutting parameters using nonlinear and linear regression models to improve the prediction accuracy. Separate equations were created for nonlinear and linear models with and without considering cutting temperature.

Table 3: Experimental data

\begin{tabular}{|c|c|c|c|c|c|c|}
\hline S.No & $\mathrm{f}(\mathrm{mm} / \mathrm{rev})$ & $\begin{array}{l}\mathrm{v} \\
(\mathrm{mm} / \\
\min )\end{array}$ & $\begin{array}{l}\mathrm{d} \\
(\mathrm{mm})\end{array}$ & $\begin{array}{l}\mathrm{R}_{\mathrm{a}} \\
(\mu \mathrm{m})\end{array}$ & $\begin{array}{l}\mathrm{T}_{\mathrm{c}} \\
\left({ }^{\circ} \mathrm{C}\right)\end{array}$ & $\begin{array}{l}\text { Training/ } \\
\text { testing }\end{array}$ \\
\hline 1 & 0.050 & 75.0 & 0.50 & 1.28 & 120.0 & Training \\
\hline 2 & 0.050 & 75.0 & 0.75 & 1.10 & 135.0 & Training \\
\hline 3 & 0.050 & 75.0 & 1.00 & 1.58 & 90.0 & Training \\
\hline 4 & 0.050 & 95.0 & 0.50 & 0.91 & 138.0 & Training \\
\hline 5 & 0.050 & 95.0 & 0.75 & 1.03 & 133.0 & Training \\
\hline 6 & 0.050 & 95.0 & 1.00 & 1.13 & 137.0 & Training \\
\hline 7 & 0.050 & 115.0 & 0.50 & 1.38 & 145.0 & Training \\
\hline 8 & 0.050 & 115.0 & 0.75 & 1.34 & 137.0 & Training \\
\hline 9 & 0.050 & 115.0 & 1.00 & 1.45 & 166.0 & Testing \\
\hline 10 & 0.075 & 75.0 & 0.50 & 1.19 & 106.0 & Training \\
\hline 11 & 0.075 & 75.0 & 0.75 & 1.09 & 136.0 & Training \\
\hline 12 & 0.075 & 75.0 & 1.00 & 1.48 & 153.0 & Training \\
\hline 13 & 0.075 & 95.0 & 0.50 & 1.45 & 114.7 & Training \\
\hline 14 & 0.075 & 95.0 & 0.75 & 1.86 & 117.0 & Training \\
\hline 15 & 0.075 & 95.0 & 1.00 & 1.82 & 153.0 & Testing \\
\hline 16 & 0.075 & 115.0 & 0.50 & 1.43 & 96.0 & Training \\
\hline 17 & 0.075 & 115.0 & 0.75 & 1.70 & 121.0 & Training \\
\hline 18 & 0.075 & 115.0 & 1.00 & 1.65 & 134.0 & Training \\
\hline 19 & 0.100 & 75.0 & 0.50 & 1.64 & 139.0 & Testing \\
\hline 20 & 0.100 & 75.0 & 0.75 & 1.13 & 140.0 & Training \\
\hline 21 & 0.100 & 75.0 & 1.00 & 1.78 & 179.0 & Training \\
\hline 22 & 0.100 & 95.0 & 0.50 & 1.77 & 121.0 & Training \\
\hline 23 & 0.100 & 95.0 & 0.75 & 1.83 & 149.0 & Training \\
\hline 24 & 0.100 & 95.0 & 1.00 & 1.53 & 155.0 & Training \\
\hline 25 & 0.100 & 115.0 & 0.50 & 1.32 & 128.0 & Testing \\
\hline 26 & 0.100 & 115.0 & 0.75 & 1.60 & 158.0 & Training \\
\hline 27 & 0.100 & 115.0 & 1.00 & 1.79 & 201.0 & Training \\
\hline
\end{tabular}


Equation (1) is the linear regression model for surface roughness without fusion; Equation (2) is the linear regression model with fusion. Equation (3) is the nonlinear regression model without fusion and Equation (4) is the nonlinear regression model with fusion.

$$
\begin{aligned}
& \mathrm{R}_{\mathrm{a}}=\left[(7.6923 . \mathrm{f})+\left(6.36015 \times 10^{-3} . \mathrm{v}\right)+(0.34697 . \mathrm{d})\right] \\
& \mathrm{R}_{\mathrm{a}}=\left[(9.16136 . \mathrm{f})+\left(7.8388 \times 10^{-3} . \mathrm{v}\right)+(0.53262 . \mathrm{d})+(-\right. \\
& \left.\left.2.88217 \times 10^{-3} . \mathrm{T}_{\mathrm{c}}\right)\right] \\
& \mathrm{R}_{\mathrm{a}}=\exp \left[(5.103176 . \mathrm{f})+\left(3.84134 \times 10^{-3} . \mathrm{v}\right)+(0.19335\right. \\
& . \mathrm{d})+(-0.534534)] \\
& \mathrm{R}_{\mathrm{a}}=\exp \left[(6.28471 . \mathrm{f})+\left(4.38229 \times 10^{-3} . \mathrm{v}\right)+\right. \\
& \left.(0.350078 . \mathrm{d})+\left(-2.439243 \times 10^{-3} . \mathrm{T}_{\mathrm{c}}\right)+(-0.46199)\right]
\end{aligned}
$$

In equations (1) to (4), Ra, f, v, d and Tc represents surface roughness, feed rate, cutting velocity, depth of cut and cutting temperature respectively. The comparison of stand errors and coefficient of determination related to both the regression models with and without fusion is presented in Table 4. Data Fit 9.0 software was used to find the coefficient of determination and other unknown coefficients in the four equations.

Table 4. Comparison of results

\begin{tabular}{|l|l|l|l|l|}
\hline Model & Type & Parameters & $\begin{array}{l}\text { Standard } \\
\text { error }\end{array}$ & $\begin{array}{l}\text { Coefficient of } \\
\text { determination }\end{array}$ \\
\hline Model 1 & Linear & f,v,d & 0.20326 & 0.90027 \\
\hline Model 2 & Linear & f,v,d,Tc & 0.19505 & 0.87504 \\
\hline Model 3 & Nonlinear & f,v,d & 0.20387 & 0.85748 \\
\hline Model 4 & Nonlinear & f,v,d, $\mathrm{T}_{\mathrm{c}}$ & 0.19411 & 0.9559 \\
\hline
\end{tabular}

From the investigation it was found that nonlinear regression model with fusion (model 4) offered the highest coefficient of determination and lowest standard error.

Model 4 was tested using the testing data present in table 3. Table 5 shows the comparison of results obtained with nonlinear model with fusion.

Table 5 Testing and comparison of surface roughness predicted by the nonlinear regression with experimental results

\begin{tabular}{|l|l|l|l|l|l|l|}
\hline \multicolumn{2}{|c|}{ Testing data } & \multicolumn{3}{|l|}{ Surface roughness $(\mathrm{Ra}) \mu \mathrm{m}$} \\
\hline $\begin{array}{l}\mathrm{f}(\mathrm{mm} \\
/ \mathrm{rev})\end{array}$ & $\begin{array}{l}\mathrm{v} \\
(\mathrm{mm} / \\
\mathrm{min})\end{array}$ & $\begin{array}{l}\mathrm{d} \\
(\mathrm{mm} \\
)\end{array}$ & $\begin{array}{l}\mathrm{Tc} \\
\left({ }^{\circ} \mathrm{C}\right)\end{array}$ & $\begin{array}{l}\text { Exp. } \\
\text { Result } \\
\text { Ra } \\
(\mu \mathrm{m})\end{array}$ & $\begin{array}{l}\text { Nonlinear } \\
\text { regression } \\
\text { with fusion }\end{array}$ & $\begin{array}{l}\% \\
\text { error }\end{array}$ \\
\hline 0.05 & 115 & 1 & 166 & 1.45 & 1.35 & 6.89 \\
\hline 0.075 & 95 & 1 & 153 & 1.82 & 1.59 & 12.63 \\
\hline 0.1 & 75 & 0.5 & 139 & 1.64 & 1.49 & 9.14 \\
\hline 0.1 & 115 & 0.5 & 128 & 1.32 & 1.50 & 13.63 \\
\hline
\end{tabular}

\section{RESULTS AND DISCUSSION}

In the present work cutting temperature was taken into consideration along with the other machining parameters to predict surface roughness. It was found that improvement in prediction accuracy is possible when more parameters are considers together with machining parameters. The work also revealed that nonlinear regression model can give better results compared to linear regression model whenever fusion is needed. The coefficient of determination value obtained was 0.90027 for the linear regression model while considering the machining parameters but this value increased to 0.9559 for nonlinear regression model by linking cutting temperature together with machining parameters.

\section{CONCLUSIONS}

In the current investigation, regression analysis was used for the prediction of surface roughness. The subsequent conclusions were obtained:

1. The prediction of surface roughness can be improved by considering more parameters along with cutting parameters.

2. A fusion model based on nonlinear regression can predict surface roughness better than regression models without fusion.

3. MCFA technique helped in promoting green environment inside the shop floor by drastically reducing mist formation. $\mathrm{s}$

\section{REFERENCES}

1 L.J. Quinn, Metal working fluids--at the cutting edge of health and safety, ASTM Standardisation News, (1992) 40-43.

2 K. Leo Dev Wins and A.S. Varadarajan, An Environment Friendly Twin-jet Minimal Fluid Application Scheme for Surface Milling of Hardened AISI4340 Steel, International Journal of Manufacturing Systems (2011) 30-45.

3 Philip, P. K., Varadarajan, A. S. and Ramamoorthy, B. 'Influence of cutting fluid composition and delivery variables on performance in hard turning using minimal fluid in pulsed jet form', Journal of the Institution of Engineers (India), (2000) 68- 72.

4 Bhuiyan M.H., Choudhury I.A., Dahari M. Monitoring the tool wear, surface roughness and chip formation occurrences using multiple sensors in turning. J. Manuf. Syst. 2014;33:476-487.

5 E. García Plaza, P. J. Núñez López, and E. M. Beamud González, Multi-Sensor Data Fusion for Real-Time Surface Quality Control in Automated Machining Systems, 2018 Dec; 18(12): 4381.

6 Segreto T., Karam S., Teti R. Signal processing and pattern recognition for surface roughness assessment in multiple sensor monitoring of robot-assisted polishing. Int. J. Adv. Manuf. Technol. 2017;9:10231033.

7 Leo Dev Wins. K, Varadarajan. A. S, and Ramamoorthy. B, 'Artificial Neural Network assisted sensor fusion model for predicting tool wear online during hard turning', 9th international symposium on measurement and quality control (9th ISMQC), IIT Madras (2007) 267 -270 .

8 Varadarajan, A.S., Ramamoorthy, B. and Philip, P.K., Formulation of a Cutting fluid for Hard Turning with Minimal Fluid Application', 20th AIMTDR conference, Birla institute of Technology Ranchi, India, (2002) 89 95. 